\title{
Why is preventive medicine exempted from ethical constraints?
}

\author{
Petr Skrabanek University of Dublin
}

\section{Author's abstract}

It is a paradox that medical experimentation on individuals, whether patients or healthy volunteers, is now controlled by strict ethical guidelines, while no such protection exists for whole populations which are subjected to medical interventions in the name of preventive medicine or health promotion. As many such interventions are either of dubious benefit or of uncertain harm-benefit balance, such as mass screening for cancers or for risk factors associated with coronary heart disease, there is no justification for maintaining the ethical vacuum in which preventive medicine finds itself at present.

\section{Ethics of human experimentation}

History shows that the medical profession seldom puts its house in order unless under pressure from the public. It may not be generally appreciated that ethical guidelines governing human experimentation were never part of the medical code until public revulsion at scandalous experiments on human 'guinea-pigs' in the 1950 s and 1960 s which were sponsored by official medical bodies (1-5). Research ethics committees owe their existence to public concern, such as that which followed exposure of the Tuskegee experiment, conducted by the US Public Health Service and the Surgeon-General on some 400 poor blacks whose syphilis had been left untreated in order to study the natural progression of the disease. The patients' (if that is the word) co-operation was obtained by the promise of a free funeral. The study was not stopped until 1972, not because the medical profession protested when they saw interim reports from this study in medical journals, but because a non-medical assistant leaked the details of the experiment to a reporter from the Associated Press (1). The subsequent Senate hearing resulted in the National Research Act, 1974, which contained specific provision for 'institutional review boards', that is ethical committees (6).

A more recent scandal, in 1989 in the United Kingdom, concerned unethical experimentation on over thirty patients with cancer, leukaemia or AIDS, in

\section{Key words}

Preventive medicine; health promotion; ethics; screening; informed consent; human experimentation. a private hospital in London, by a doctor who charged $£ 10,000$ for a course of unproved treatment (7). Again, $\vec{\sigma}$ it was an investigative journalist and television who brought this affair into the open (7).

Despite the nominal supervision of human 0 experimentation by ethical committees, medical research on humans is often carried out in 0

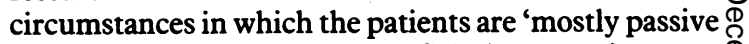
participants, unwitting beneficiaries, or ignorant $\stackrel{\mathscr{D}}{\mathcal{S}}$ victims' (8). Herxheimer called for public involvement in the ethical issues of clinical trials (8). According to Tunkel, who is a barrister, a patient who takes part in $\vec{\varnothing}$ a trial and suffers adverse effects has no legal right $\$$ compensation and should be informed beforehant accordingly (9).

There is no reason why this proper concern about the rights of patients in clinical trials to be fully informed about the nature of the experiment, its expected benefits and its potential harms should not be $\stackrel{2}{\Rightarrow}$ extended to population experiments conducted in the $\frac{0}{3}$ name of health promotion or preventive medicine.

\section{The ethical vacuum of preventive medicine}

At present, State or private bodies conducting mass $\overline{\bar{\Phi}}$ preventive interventions have no obligation to inform: the healthy participants that they are the subjects of 3 . experiments of uncertain outcome and potential harm. As the interventions are 'preventive medicine', they are automatically exempted from ethical constraints.

For example, in the Breast Cancer Detection Project set up in 1973 by the National Cancer Institute and theo American Cancer Society to screen a quarter of a million healthy women, the possible risks of mammography were not explained to them nor were 0 they told about the lack of evidence for the benefit of mammography in women under the age of fifty (10). In subsequent similar trials in different countries, no mention was made in the published reports whether the participants received adequate information about? the uncertainties of benefit. Such information could, of course, jeopardise the 'compliance' rate and theo' 'throughput'.

The reasons for the ethical limbo in which preventive medicine finds itself are in part historical and in part political. Historically, preventive medicine grew out of the State's interest in protecting its 
productive, healthy citizens by the segregation of those who suffered contagious diseases such as leprosy or plague. Early preventive medicine was synonymous with medical policing. In the 19th century, prostitutes were screened by police surgeons not for the sake of their own health but for the protection of their clients. Screening for disease was initially used as a sieve to separate the healthy and useful from the weak and useless, whether on behalf of insurance companies (to exclude poor risks), armies (to weed out weaklings) or employers (to keep up productivity). In 1900, Lord Rosebery, an important political figure of the time, saw the problem of national health in terms of crude social Darwinism; in a speech at the University of Glasgow he stated: 'Where you promote health and arrest disease, where you convert an unhealthy citizen into a healthy one, where you exercise your authority to promote sanitary conditions and suppress those which are the reverse, you, in doing your duty are also working for the Empire ... Health of mind and body exalt a nation in the competition of the universe. The survival of the fittest is an absolute truth in the conditions of the modern world' (11).

Another reason why preventive medicine has so far been exempted from ethical considerations may be the half-truth that prevention is better than cure, with the implication that any possible disadvantage is more than repaid by the ensuing benefit. While this may be true for some preventive measures, such as immunisation or common-sense hygiene, it may not apply for other preventive activities, such as screening for cancer or for risk factors for coronary heart disease. Population interventions aimed at reducing coronary heart disease have been a spectacular failure (12), and, as regards cancer prevention, despite much military rhetoric and decades of expensive crusades, the war on cancer has been declared lost in at least one authoritative analysis (13). We should not confuse 'prevention' with 'hopes of prevention'. Uncovering problems for which there is no effective treatment is not preventive medicine but a medical contribution to ill-health.

\section{Could preventive medicine be dangerous to health?}

The proverb, 'a stitch in time saves nine', may be sound advice for mending socks but it makes little sense if a thousand people need one stitch (in its medical equivalent) to save one person from nine stitches. Translated into financial terms, 10 pence of prevention a day is not cheaper than $£ 10$ for a cure a year. Many preventive measures, such as cancer screening, require regular visits to the doctor or to a special clinic throughout life, may involve unpleasant or dangerous procedures, cause iatrogenic morbidity (and perhaps even death), and result in the medicalisation of life for all.

It is naively presumed that preventive medicine is a risk-free pursuit, which, at worst, may do no good. This is hardly a valid argument. As one wit observed, what would you say to a salesman who was offering you a new electric gimmick which failed to work on demonstration, when he beamed at you and said, 'but it didn't blow the fuse!'

Becker warned that health promotion 'fosters a dehumanising self-concern which substitutes personal health goals for more important, humane, societal goals. It is a new religion in which we worship ourselves, attribute good health to our devoutness, and view illness as just punishment for those who have not yet seen the Way' (14).

The harm of preventive medicine has been discussed and documented by various authors (15-18). Even something so innocuous as the adoption of a cholesterol-lowering diet, as prescribed by the American Heart Association, could increase rather than decrease the risk of coronary heart disease in women (19). The logical non-sequitur of lowering blood cholesterol in healthy people because cholesterol is a risk marker for coronary heart disease led to the tragedy of the clofibrate trial, in which significantly more healthy men treated with clofibrate died than the controls (12). It is unlikely that the men were informed beforehand about the possibility that their participation in the trial might be harmful to them and even fatal.

As up to 50 per cent of a population (depending on an arbitrary definition of 'elevated' cholesterol) is the potential target for mass intervention by preventionists (20), the pharmaceutical industry is eagerly anticipating the profits from the mountain of cholesterol-lowering medicaments which will be prescribed by doctors. Long-term effects of such treatment are not known but are unlikely to be harmless.

A similar situation exists in screening for hypertension. Hypertension is not a disease but an arbitrarily defined physical measure: not surprisingly, according to some 'experts', up to 40 per cent of adult populations are 'hypertensive'. The measurement of blood pressure in practice is uncertain and imprecise and consequently many people are labelled as 'hypertensive' on false grounds (21). The effects of such labelling are serious: they include the erosion of the sense of well-being, lowered sense of self-esteem, marital problems, reduction in earning power, and the adoption of a 'sick role' in a previously healthy person (22).

Women are particularly vulnerable to the exploits of preventive medicine. Great pressure is put on them to undergo regular gynaecological examinations, physical examinations of their breasts and to practise in addition breast self-examination. Some women doctors are starting to question the 'well-womanising' crusade, in which the major casualties are the women themselves (23).

Breast cancer screening has an adverse harm-benefit ratio, but women are told nothing about the nature and the extent of risks; these include unnecessary operations due to false-positive results, which far outnumber true-positive findings $(24,25)$. Schmidt 
calculated that for each woman who benefits from screening, 18 women have to live longer with the knowledge of their incurable disease ('extra cancer years') because of earlier diagnosis by screening. This estimate was based on the best mammographical results, which have not been reproduced in other centres. Schmidt also pointed out, in his detailed critique of the Swedish mammographic trial, that over 100 women would have needle biopsy and further surgical investigations for each woman who could expect benefit in terms of a cure (26).

In cervical cancer screening, the possible benefits are debatable and may be non-existent, but the harms are common and largely ignored (27). The principal author of the British National Health Programme, Alwyn Smith, stated that 'it is absurd to conduct a screening test in such a way that nearly forty women are referred for an expensive and possibly hazardous procedure for every woman who is at risk of developing serious disease' (28). Yet this absurd situation continues unabated, without anyone recognising an obligation to the women to inform them about the true state of the 'art'.

Breast self-examination has never been shown to reduce mortality from breast cancer and there are theoretical reasons why it is unlikely to do so, because by the time breast cancer is palpable the tumour will have been growing for a long time. In the UK trial of early breast cancer detection this method was proved to be worthless (29), and it could be argued that it is actually harmful, particularly in younger women, as it leads to unnecessary anxiety and unnecessary medical and surgical intervention in the vast majority of women who discover an abnormality during the ritual of selfexamination (30). Yet, as with other unproved preventive measures, cancer societies and other wellmeaning but misguided groups are allowed freely to broadcast misleading propaganda. Breast cancer screening recommendations were described by one editorialist as 'a confusing mixture of half-truths, unsupported by the scientific evidence to date, which only adds to the anxiety and uncertainty that always seems to cloud rational discussion of what knowledge we do - or especially do not - have about breast cancer' (31).

Unfortunately, optimistic even though untrue information about prevention is more believable than sober, grim facts, and as such is readily exploited by medical profit-making organisations. In Ireland, 'executive health screening' is offered in a number of private clinics: charges range from $£ 170$ in the Charlemont Clinic to $£ 200$ in the Blackrock Clinic for men, while women who have in addition an optional cervical smear and mammography are charged $£ 250$ (32). BUPA in the UK run the following advertisement in the national papers: 'If you are almost positively certain that you're probably healthy, why not talk to BUPA? ... Health assessment costs $£ 232$ for men and $£ 268$ for women ... So don't kid yourself that you're healthy. Find out for sure by filling in the coupon below'.

In the absence of any ethical guidelines more and more unsuspecting people will be caught in the 'preventive' net.

In search of the ethics of preventive medicine

Population interventions which have as their goal the prevention of coronary heart disease and many cancers $\widehat{\Phi}$ should be classified as population experiments and the same guidelines should apply to them as to clinical ${ }^{\infty}$ trials. That such interventions are of an experimental $\overrightarrow{0}$ nature and of uncertain benefit is made clear by the fact $\overrightarrow{\vec{\omega}}$ that they are often tested in randomised controlled $\stackrel{\omega}{\omega}$ trials.

If a healthy volunteer, or a patient, has a right to be ${ }^{\overparen{D}}$ fully informed about the risks and benefits of the trial $\vec{\sigma}$ in which he takes part, even more meticulous attention ? $^{-}$ should be paid to the rights of a whole population of $\overrightarrow{0}$ healthy people who are subjected to mass prevention ${ }_{\circ}$ programmes and intervention, however well meant.

As Gillon pointed out, health education (and this $\vec{\nabla}$ applies equally to all areas of preventive medicine) is 'as heavily bedevilled by moral issues as is any other area $\stackrel{\Phi}{3}$ of health care', and it should 'conform, as much as any음 other area of medical care, to the medico-moral norms $\stackrel{\mathbb{D}}{-}$ of respect for people's autonomy, beneficence, non- $\overrightarrow{0}$

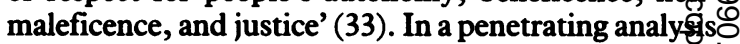
of the health-promotion industry, Williams noted thitio the field is riddled with serious conceptual and ethicislo problems, and expressed concern about the lack $\overrightarrow{\text { of }} \overrightarrow{\bar{O}}$ protection of the public (by a medical equivalent of theo Trades Description Act) against the hard-selli techniques of health salesmen (34).

A forum should be set up enabling representatives of $\vec{\partial}$ the public, and of the medical and legal professions, to identify the ethical problems posed by new developments in preventive medicine and health promotion.

Dr Skrabanek is Senior Lecturer in Community Health at를. Trinity College, Dublin. Address for correspondence: $\operatorname{Dr} P$. Skrabanek, Department of Community Health, Trinity College, Dublin 2, Ireland.

\section{References}

(1) Jones J H. Bad blood. The Tuskegee syphylis experiment. New York: The Free Press, 1981.

(2) US House of Representatives Subcommittee. Americano nuclear guinea pigs: three decades of radiation experiments $\mathrm{N}$ on US citizens. Washington: US Government Printingo Office, 1986.

(3) Beecher H K. Ethics and clinical research. New England $\frac{0}{\Phi}$ journal of medicine 1966; 274: 1354-1360.

(4) Gillmor D. I swear by Apollo. Dr Ewen Cameron and the CIA-brainwashing experiments. Montreal: Eden $\bar{\sigma}$ Press, 1987.

(5) Pappworth M H. Human guinea pigs. Experimentation on man. Harmondsworth: Penguin Books, 1969.

(6) Capron A. Research ethics and the law. In: Berg $\mathrm{K}_{2} \bar{\sigma}$ Tranøy K E, eds. Research ethics. New York: A Liss, 1983: 17. 
(7) Anoymous. Scandal in Southwark. Lancet 1989; i: 856857.

(8) Herxheimer A. The rights of the patient in clinical research. Lancet 1988; ii: 1128-1130.

(9) Tunkel V. Drug trials: who takes the risk? Lancet 1989; ii: 609-611.

(10) Carbone P P. A lesson from the mammography issue. Annals of internal medicine 1978; 88: 703-704.

(11) Eyler J M. Poverty, disease, responsibility: Arthur Newsholme and the public health dilemmas of British liberalism. Millbank quarterly 1989; 67 (suppl 1): 109_ 129.

(12) McCormick J, Skrabanek P. Coronary heart disease is not preventable by population interventions. Lancet 1988; ii: 839-841.

(13) Bailer J C, Smith E M. Progress against cancer? New England journal of medicine 1986; 314: 1226-1232.

(14) Becker M H. The tyranny of health promotion. Public health review 14: 15-25.

(15) Skrabanek P. Mass screening in women: more harm than benefit? In: Stoll B, ed. Social dilemmas in cancer prevention. London: Macmillan Press, 1989: 67-73.

(16) Marteau T M. Psychological costs of screening may sometimes be bad enough to undermine the benefits of screening. British medical journal 1989; 299: 527.

(17) Stoate H G. Can health screening damage your health? Fournal of the Royal College of General Practitioners 1989; 39: 193-195.

(18) Tymstra T. False positive results in screening tests: experiences of parents of children screened for congenital hypothyroidism. Family practice 1986; 3: 92 96.

(19) Crouse J R. Gender, lipoproteins, diet, and cardiovascular risk. Sauce for the goose may not be sauce for the gander. Lancet 1989; i: 318-320.

(20) Smith W C S, Kenicer M B, Davis A M, Evans A E, Yarnell J. Blood cholesterol: is population screening warranted in the UK? Lancet 1989; i: 372-373.

(21) Anonymous. More on hypertensive labelling [editorial]. Lancet 1985; i: 1138-1139.

(22) Alderman M H, Lamprot B. Labelling of hypertensives: a review of the data. Fournal of clinical epidemiology 1990; 43: 195-200.

(23) McCullogh S. Useless smear campaign. The spectator $1989 \mathrm{Feb} 11: 20-23$.

(24) Skrabanek P. The debate over mass mammography in Britain. The case against. British medical journal 1988; 297: 971-972.

(25) Skrabanek P. Mass mammography: the time for reappraisal. International journal of technology assessment in health care $1989 ; 5: 423-430$.

(26) Schmidt J G. The epidemiology of mass breast cancer screening - a plea for a valid measure of benefit. Foumal of clinical epidemiology 1990; 43: 215-225.

(27) Skrabanek P. Cervical cancer screening: the time for reappraisal. Canadian journal of public health 1988; 79: 86-88.

(28) Smith A. Cervical cytology screening. British medical journal 1988; 296: 1670.

(29) UK trial of early detection of breast cancer group. First results on mortality reduction in the UK trial of early detection of breast cancer. Lancet 1988; ii: 411-416.

(30) Frank J W, Mai V. Breast self-examination in young women: more harm than good? Lancet 1985; ii: 654-657.

(31) Dixon T. Breast cancer: the debate continues. Canadian family physician 1987; 33: 817-818.

(32) Anonymous. Health screening. Irish medical times (financial supplement) 1989 May.

(33) Gillon $\mathbf{R}$. Health education: the ambiguity of the medical role. In: Doxiadis $\mathrm{S}$, ed. Ethics in health education. Chichester: Wiley, 1990: 29-41.

(34) Williams G. Health promotion - caring concern or slick salesmanship? fournal of medical ethics 1984; 10: 191195. 